\section{Response to Zhang et al.}

We appreciate the thoughtful comments by Zhang and colleagues ${ }^{1}$ regarding our article "Detection of iron deficiency in children with Down syndrome." ${ }^{2}$ We agree that ferritin, while a useful measure for identifying iron deficiency/iron deficiency anemia, can be elevated in the setting of comorbidities. ${ }^{3}$ Therefore, the interpretation of its value needs to be considered in the context of the child's whole medical history and evaluation. Similarly, comorbidities such as malnutrition may falsely lower serum transferrin. ${ }^{4}$ As noted in our paper, we agree that bone marrow evaluation is the gold standard for evaluating iron stores, but this is invasive and not practical. At our institutions, we do make use of soluble transferrin receptor measurement to help distinguish iron deficiency anemia versus anemia of chronic disease. To be cost-efficient these measures are not obtained on all patients, but are introduced in a tiered evaluation as needed. We agree that many other factors can affect red cell distribution width (RDW); however, similar to the utility of ferritin, the RDW value needs to be considered in the setting of the child's entire medical history and condition.

In summary, through our investigation of a large number of individuals with Down syndrome at multiple different institutions, we provide evidence to support a systematic approach of laboratory testing and clinical follow up. However, for children with comorbidities, referral to a provider with expertise in hematology, including review of the peripheral blood smear and a trial of iron replacement over time, can help clarify the extent, etiology, and management of an individual's iron deficiency and iron deficiency anemia. Further research will help to parse out the contributions of nutrition, infection, autoimmunity, metabolic diseases, antibiotic usage, and other variables in children with Down syndrome and iron deficiency/iron deficiency anemia.

\section{DISCLOSURE}

B.G.S. occasionally consults on the topic of Down syndrome through Gerson Lehrman Group. He receives remuneration from Down syndrome nonprofit organizations for speaking engagements and associated travel expenses, and receives annual royalties from Woodbine House, Inc., for the publication of his book, Fasten Your Seatbelt: A Crash Course on Down Syndrome for Brothers and Sisters. Within the past two years, he has received research funding from F. Hoffmann-La Roche, Inc. and LuMind Research Down Syndrome Foundation to conduct clinical trials for people with Down syndrome. He is occasionally asked to serve as an expert witness for legal cases where Down syndrome is discussed, and serves in a nonpaid capacity on the Honorary Board of Directors for the Massachusetts Down Syndrome Congress, the Board of Directors for the Band of Angels Foundation, and the Professional Advisory Committee for the National Center for Prenatal and Postnatal Down Syndrome Resources. He also a sister with Down syndrome. K.Z. receives support from the National Institutes of Health (National Institute of Child Health and Human Development (K23 HD091398, HHSN275201000003I), the Duke Clinical and Translational Science Award (KL2TR001115-03), and industry for neonatal and pediatric drug development (www.dcri.duke.edu/research/ coi.jsp). The other authors declare no conflicts of interest.

Publisher's note Springer Nature remains neutral with regard to jurisdictional claims in published maps and institutional affiliations.

Sarah J. Hart, PhD, CGC (D) ${ }^{1}$, Kanecia Zimmerman, $M D, M P H^{1}$, Corinne M. Linardic, $M D, P h D^{1,2}$, Sheila Cannon, $M E d^{3}$, Anna Pastore, $\mathrm{PhD}^{4}$, Vasiliki Patsiogiannis, $B A^{5}$, Paolo Rossi, $M D, P h D^{4,6}$, Stephanie L. Santoro, $M D^{5,7,8}$, Brian G. Skotko, $M D, M P P^{5,8}$, Amy Torres, $B S^{5}$, Diletta Valentini, $M D^{6}$, Kishore Vellody, $M D^{3}$, Gordon Worley, $M D^{1}$ and Priya S. Kishnani, $M D^{1}$

${ }^{1}$ Department of Pediatrics, Duke University Medical Center, Durham, NC, USA; ${ }^{2}$ Department of Pharmacology and Cancer Biology, Duke University Medical Center, Durham, NC, USA; ${ }^{3}$ Down Syndrome Center of Western Pennsylvania, University of Pittsburgh Medical Center Children's Hospital of Pittsburgh, Pittsburgh, PA, USA; ${ }^{4}$ Laboratory of Molecular Genetics and Functional Genomics, Division of Genetic and Rare Disease, Bambino Gesù Children's Hospital and Research Institute, Rome, Italy; ${ }^{5}$ Down Syndrome Program, Division of Medical Genetics and Metabolism, Department of Pediatrics, Massachusetts General Hospital, Rome, Italy; ${ }^{6}$ Department of Pediatrics, Bambino Gesù Children's Hospital and Research Institute, Rome, Italy; ${ }^{7}$ Division of Genetics, Nationwide Children's Hospital, Columbus, OH, USA; ${ }^{8}$ Department of Pediatrics, Harvard Medical School, Boston, MA, USA. Correspondence:

Sarah J. Hart (sarah.hart@duke.edu)

\section{REFERENCES}

1. Zhang W, Liu Y, Zeng, D. Detection of iron deficiency in children with Down syndrome. Genet Med. In Press.

2. Hart SJ, Zimmerman K, Linardic CM, et al. Detection of iron deficiency in children with Down syndrome. Genet Med. 2019 Aug 16; https://doi.org/ 10.1038/s41436-019-0637-4 [Epub ahead of print].

3. Baker RD, Greer FR. Committee on Nutrition American Academy of P. Diagnosis and prevention of iron deficiency and iron-deficiency anemia in infants and young children (0-3 years of age). Pediatrics. 2010;126: 1040-50.

4. Bharadwaj S, Ginoya S, Tandon P, et al. Malnutrition: laboratory markers vs nutritional assessment. Gastroenterol Rep (Oxf). 2016;4:272-80.

Advance online publication 12 November 2019. doi:10.1038/s41436-019-0690-Z 